Original Article

\title{
KNOWLEDGE AND PREVALENCE OF DIABETES AND HYPERTENSION AM ONG ADULTS IN SELECTED VILLAGES OF UDUPI DISTRICT - KARNATAKA
}

\author{
Suja Karkada ${ }^{1}$, Navaneetha ${ }^{2} \&$ Ansuya $^{3}$ \\ ${ }^{1}$ Assistant Professor, RAKCON, UAE,,${ }^{2}$ Associate Professor, ${ }^{3}$ Assistant Professor, Department of community Health \\ Nursing, M anipal College of Nursing, Manipal University, Manipal - 576 014, Karnataka, India \\ Correspondence : \\ Ansuya \\ Assistant Professor, Department of Community Health Nursing, Manipal College of Nursing, \\ Manipal University, Manipal - 576 014, Karnataka, India. \\ E-mail : bhushi403@gmail.com
}

\begin{abstract}
:
Objectives : to assess the prevalence and knowledge of diabetes and hypertension among adults and to find the association between knowledge level and variables.

Methods : Descriptive survey was conducted among adults in the selected villages of Udupi district during July 2009- July 2010. The study subjects were interviewed to collect the details with a questionnaire. Total 385 adults were selected by non- probability convenient sampling technique. Data were entered in SPSS11.5 version and analysed using descriptive and inferential statistics.

Results : Out of 385 adults, $27.8 \%$ of adults were females and $72.2 \%$ had their education up to primary level. Majority (82.2\%) of the adults were having unskilled occupation and $96 \%$ of them had exposure to mass media. Majority (50.4\%) of them had average knowledge on diabetes mellitus and prevalence was found to be only $5 \%$. Majority (50.6\%) of the sample had average level of knowledge about hypertension and the prevalence of hypertension was 19.5\%. Result shows that there is no significant association between knowledge and selected variables.
\end{abstract}

Key words: Hypertension, Diabetes, Prevalence, Knowledge

\section{Introduction:}

Diabetes mellitus is the single most important metabolic disease recognized worldwide as one of the leading cause of death and disability. The problem has reached pandemic proportions. Type 2 diabetes is the commonest form of diabetes constituting almost $90 \%$ of diabetic population. Prevalence of diabetes in the adults worldwide was estimated to be $4.0 \%$ in 1995 and expected to be $5.4 \%$ by the year 2025. Its incidence is higher in developing countries than developed countries. It has been estimated that presently 19.4 million individuals are affected by

Access this article online Quick Response Code

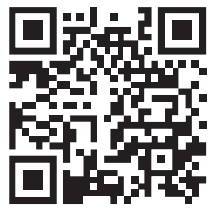
diabetes and these numbers are expected to increase to 57.2 million by the year 2025 (one-sixth of the world total). World Health Organization (WHO) has already declared India as the global capital of diabetes and WHO has revised the predicted number of diabetics in India to be nearly 80 million by $2030^{1}$.

Hypertension poses a significant risk for the development of heart disease and chronic kidney disease. Worldwide, the major causes for chronic kidney disease are diabetes mellitus and hypertension. A recent estimate suggests that approximately one billion adults have hypertension (333 million in economically developed and 639 million in economically developing countries); with the highest prevalence being noted in Eastern Europe and the Latin American/Caribbean region ${ }^{2}$ The global response to this challenge is prevention, early detection, and treatment. Hypertension is a massive public health problem in India, incurring tremendous physical, emotional and financial loss. Due to limited resource allocation in the health sector, the available facilities seem to be scarcely available. A previous study conducted among the middle aged 
population of Kerala in 2003 showed $54.5 \%$ prevalence of hypertension $^{3}$

\section{Methods \& Materials :}

A community based cross sectional descriptive survey study was carried out during the year 2009-2010 in Athrady, Marne \& Hirebettu villages of Udupi District. A non- probability convenient sampling was used to select 385 samples and collect data from them by using structured and validated knowledge questionnaire on diabetes mellitus \& hypertension. The adults were between the age group of 40-60 years, residing in the villages, willing to participate and present at home during the time data collection. An adult who could not read Kannada (local language) was excluded from the study.

Demographic Proforma consisted of age, education, occupation, food habits and exposure to mass media.

Tables 1: Frequency \& Percentage of distribution of samples characteristics.

$\mathrm{N}=385$

\begin{tabular}{|l|l|c|c|}
\hline Variables & & Frequency & Percent \\
\hline Gender & male & 107 & 27.8 \\
\cline { 2 - 4 } & female & 278 & 72.2 \\
\hline \multirow{4}{*}{ Education } & illiterate & 74 & 19.2 \\
\cline { 2 - 4 } & primary & 203 & 52.7 \\
\cline { 2 - 4 } & high school & 75 & 19.5 \\
\cline { 2 - 4 } & PUC & 16 & 4.2 \\
\cline { 2 - 4 } & graduation & 15 & 3.9 \\
\cline { 2 - 4 } & PG & 2 & .5 \\
\hline \multirow{4}{*}{ Occupation } & unskilled & 318 & 82.6 \\
\cline { 2 - 4 } & skilled & 53 & 13.8 \\
\cline { 2 - 4 } & profession & 14 & 3.6 \\
\hline mass media & not exposed & 4 & 1.0 \\
\cline { 2 - 4 } & exposed & 381 & 98.7 \\
\cline { 2 - 4 } & vegetarian & 82 & 21.3 \\
\hline Diet & non-vegetarian & 61 & 15.8 \\
\cline { 2 - 4 } & mixed & 242 & 62.9 \\
\hline
\end{tabular}

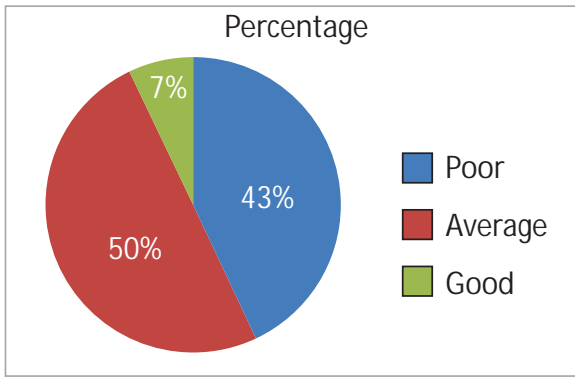

Fig 1: Knowledge score on Diabetes M ellitus
Fifteen M ultiple Choice Questions (M CQ) were developed to assess the knowledge on diabetes mellitus and 15 M CQ for hypertension; each with maximum score of 15 and minimum score of zero. Knowledge scores were arbitrarily classified as low (0-5), average (6-10) and good (11-15) level. Each individual was screened for diabetes mellitus by performing Benedict's test and for hypertension by monitoring the blood pressure using calibrated sphygmomanometer.

The reliability of the tool was determined by test-retest method. The reliability co-efficient was $r=0.70$. Administrative permission was obtained to collect the data from the concerned authorities. A written consent was also obtained from the eligible participants for this study and data were collected between July 2009 and July 2010. Data were analyzed using descriptive and inferential statistics.

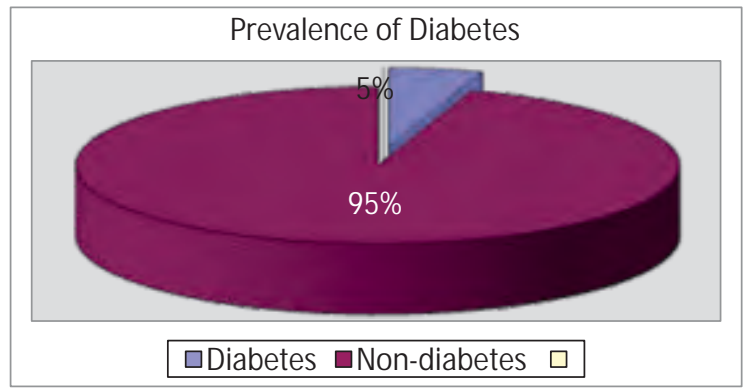

Fig 2 : Prevalence of diabetes

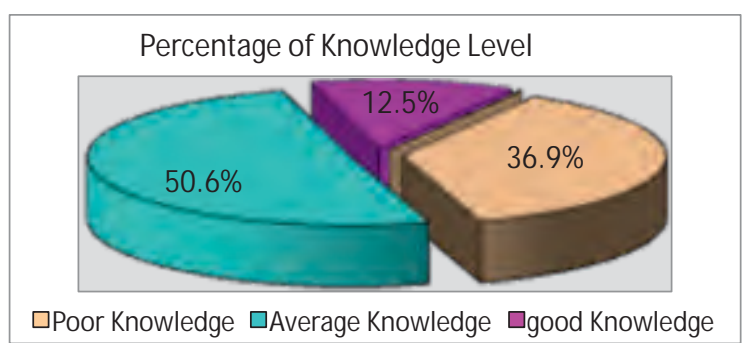

Figure 3 : Knowledge level regarding Hypertension

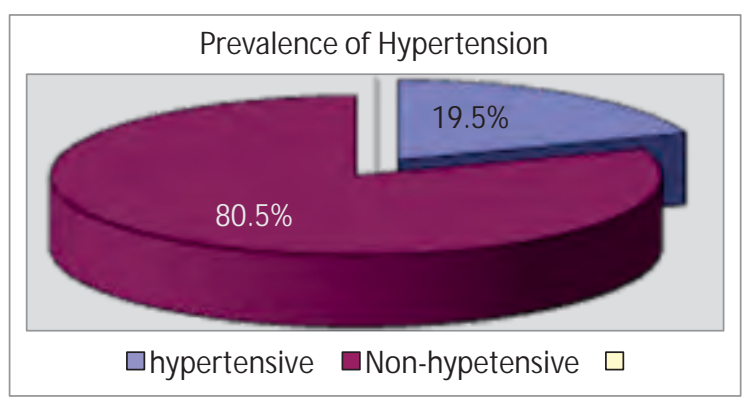

Figure 4 - Prevalence of Hypertension 
Table 2 : Chi-Square test computed between knowledge score of adults and selected variables

\begin{tabular}{|l|l|c|c|c|c|c|c|}
\hline Variables & Poor & Average & Good & Chi. Sq & df & P-value \\
\hline \multirow{3}{*}{ Gender } & male & 50 & 50 & 7 & 2.25 & 2 & 0.31 \\
\cline { 2 - 7 } & female & 111 & 144 & 23 & & & \\
\hline Education & illiterate & 39 & 32 & 3 & 7.7 & 4 & 0.10 \\
\cline { 2 - 6 } & primary & 85 & 101 & 17 & & & \\
\cline { 2 - 6 } & $\begin{array}{l}\text { high school } \\
\text { \&above }\end{array}$ & 37 & 61 & 10 & & & \\
\cline { 1 - 7 } Occupation & unskilled & 138 & 156 & 24 & 1.86 & 2 & 0.45 \\
\cline { 2 - 5 } & skilled & 23 & 38 & 6 & & & \\
\hline
\end{tabular}

\section{Results:}

Out of 385 samples $27.8 \%$ of adults were females and $72.2 \%$ had their education up to Primary school level. Majority (82.2\%) of the adults were having unskilled occupation, $62 \%$ were consuming mixed diet and $96 \%$ of them had exposure to mass media (Table1). Majority (50.4\%) of them had average knowledge on diabetes mellitus and hypertension (50.6\%) (Fig. 1\&3). The prevalence of hypertension was $19.5 \%$ and diabetes was $5 \%$ (fig 2\&4). Result shows that there was no significant association between knowledge on diabetes mellitus and selected variables (Table 2).

\section{Discussion :}

Diabetes mellitus and cardiovascular diseases lead the list of all non-communicable diseases. A study done by Jali M V found that prevalence of diabetes was more among males (10.38\%) compared with females (7.90\%) but the findings

\section{References :}

1. World Health Organization, Regional Office for South East Asia. Health Situation in South East Asia Region (1998-2000), Regional office for SEAR New Delhi, 2002. Available from: http://www.searo.who.int /LinkFiles/Health_Situation_book.pdf. [cited in 2002].

2. Kearney $\mathrm{PM}^{1}$, Whelton $\mathrm{M}$, Reynolds $\mathrm{K}$, M untner $\mathrm{P}$, Whelton PK, He J. Global burden of hypertension: analysis of worldwide data. Lancet. In press

3. Zachariah MG, Thankappan KR, Alex SC, Sarma PS, Vasan RS. Prevalence, correlates, awareness, treatment, and control of hypertension in a middle aged urban population in Kerala. Indian Heart J 2003; 55:245-51.

4. Jali MV, Kambar S. Prevalence of diabetes amongst the family members of known diabetics. International journal of diabetes in developing countries:26(2) 81-85, 2006

5. Vimala $A^{1}$, Ranji SA, Jyosna MT, Chandran V, M athews SR, Pappachan $J M$. - The prevalence, risk factors and awareness of hypertension in an urban population of Kerala (South India). 2009; 20(4): 685-89

6. Todkar SS, Gujarathi VV, Tapare VS. Period prevalence and sociodemographic factors of hypertension in rural Maharashtra: A crosssectional study. 2009; 34(3):184-87 were statistically not significant. According to the age, the prevalence of diabetes was more in the age groups 30-39 (9.62\%) and $40-49$ years (18.24\%). This shows that the changing trends in disease occurrence are affecting the people of productive age group and making them socioeconomically inefficient ${ }^{4}$.

The overall prevalence of hypertension in the study subject was $19.5 \%$ (75 of 385). A similar study was conducted in Trivandrum, Kerala and the result showed that the prevalence of hypertension is high(47\%) but the awareness among the people is low ${ }^{4}$ which is contrary to the present study findings where the prevalence is $19.5 \%$ only and awareness is average ${ }^{5}$.

Another study was conducted in Aurangabad, M aharashtra from June 2005 to December 2006 among 1297 persons and it showed that the prevalence was $7.24 \%$.

\section{Conclusion:}

The worldwide prevalence of diabetes mellitus and hypertension has risen dramatically in the developing countries over the past two decades. Regular screening of adults is essential for early detection and care. There are limited studies on awareness of diabetes and hypertension in rural communities. India is going to face a big challenge posed by these diseases and its complications. 